\title{
Facial Emotion Recognition in Children with
}

\section{Externalising Behaviours: A Systematic Review}

Sara Cooper, Christopher W. Hobson, \& Stephanie H.M. van Goozen

School of Psychology, Cardiff University 


\begin{abstract}
Difficulties in facial emotion recognition (FER) are associated with a range of mental health and antisocial presentations in adolescents and adults (e.g., Dawel et al., 2012). Externalising behaviours in children are often one of the earliest signs of risk for the development of such difficulties.
\end{abstract}

This paper systematically reviews the evidence (from both group and correlational studies) for whether there is a relationship between FER and externalising behaviours in preadolescent children (aged 12 and under), both across and within externalising behaviour domains (hyperactivity, conduct problems, callous-unemotional traits, and aggression). Four electronic databases were searched producing 1296 articles. Articles were included if they used validated measures of FER and externalising behaviours. Sixteen papers met criteria for inclusion in the review.

Overall, the results suggested FER problems are present in ADHD, CP and callousunemotional presentations, and in samples of children with higher levels of externalising problems rather than in community samples. However, there was no consistent evidence for specific emotions being implicated in the studies reviewed.

Clinically, the findings suggest that FER difficulties are commonly associated with externalising behaviours, and hence this review offers some support that FER deficits could be a relevant target of intervention for externalising behaviours. However, more longitudinal studies are required, that control for other variables that might underlie FER difficulties (e.g., IQ or basic Theory of Mind abilities), to inform our knowledge of whether FER difficulties are a causal factor in externalising behaviours. 


\section{Introduction}

Appropriate social interaction and adjustment relies on the accurate identification of other's emotional expressions (Saarni, 1999). Difficulties with emotion recognition are well documented in both adolescents and adults presenting with a range of mental health and antisocial presentations (e.g., Dawel et al., 2012). One of the earliest signs of such social or emotional adjustment difficulties in childhood is the presence of 'externalising behaviours' which are problematic behaviours directed towards an individual's environment.

Externalising behaviours are also known to be linked to adjustment difficulties later in life (e.g., Frick, 2012).

This systematic review will focus on the relationship between facial emotion recognition (FER) and externalising behaviours in pre-adolescent children. Greater insight into this relationship is needed to inform effective interventions for children during crucial stages in their development.

\section{Emotion Recognition}

Emotions can be recognised from various cues including facial expressions, body postures, gestures, and tone of voice. Emotion recognition (ER) has been conceptualised as comprising four skills: awareness that an emotion has been expressed, labelling prototypical emotions, labelling non-typical emotions, and using contextually relevant information in identifying and labelling emotions (Castro, Cheng, Halberstadt, \& Gruhn, 2016). ER is an important component of 'cognitive empathy' which is the ability to rationally understand and recognise the emotional state, and to take the perspective of others (Bons et al., 2013). ER represents the early use of social cues on which children's subsequent behavioural responses and relationships depend (Cicchetti, 2016). Thus, the degree to which emotional skills 
develop in childhood has significant implications for children's lifelong social competence (Denham et al., 2003; Izard et al., 2001).

\section{Facial Emotion Recognition}

Facial expressions are one of the most powerful ways to communicate emotions (Frith, 2009), and continue to develop throughout childhood. By preschool, most children can label another's feelings by looking at their face (Parker, Mathis, \& Kupersmidt, 2013). By the age of 4 or 5 most children can reliably identify the six basic emotions of happiness, sadness, anger, fear, surprise and disgust across a range of stimuli (Camras et al., 1988; MacDonald, Kirkpatrick, \& Sullivan, 1996; Russell \& Widen, 2002; Schultz, Izard, \& Ackerman, 2000). Some studies suggest that near-adult levels of Facial Emotion Recognition (FER) are achieved before adolescence (Rodger, Vizioli, Ouyang, \& Caldara, 2015).

\section{Externalising Behaviours}

"Externalising Behaviours" include the constructs of Disruptive Behaviour Disorders (DBD), hyperactivity, conduct problems (CP), aggressive behaviours and CallousUnemotional (CU) traits, as well as the DSM-V (APA, 2013) diagnostic categories of Oppositional Defiant Disorder (ODD), Conduct Disorder (CD), and Attentiondeficit/Hyperactivity Disorder (ADHD). Externalising behaviours in childhood are associated with a range of poor outcomes in later life such as persistent antisocial behaviour, imprisonment, mental health difficulties, and poorer social functioning (e.g., Frick, 2012; Frick \& Viding, 2009; Frick \& White, 2008; Mannuzza and Klein, 2000), and result in a large economic burden to society (e.g., Odgers et al., 2007).

Within the umbrella of externalising problems, the most widely studied diagnostic group is children with hyperactivity or those who meet the criteria for ADHD, a diagnosis characterised by hyperactivity, impulsivity, and/or inattention (Leibson \& Hall Long, 2003; 
Wilens \& Spencer, 2010). CP refers to angry, defiant, antisocial, aggressive and norm violating behaviours in children and adolescents which subsume ODD and CD (Lorber, 2004). ODD refers to a recurrent pattern of negative, defiant, disobedient and hostile behaviour towards others in authority, whereas $\mathrm{CD}$ describes more severe behaviour, where basic rights or norms are violated. ODD can be a precursor to CD which is in turn often a precursor to antisocial personality disorder in adulthood (de Wied, Gispen-de Wied, \& van Boxtel, 2010). CU traits are purported to measure the childhood version of the affective dimension of psychopathy as originally measured in adults through the Psychopathy Checklist-Revised (Hare, 1991). CU traits are characterised by callousness, a lack of empathy and guilt, and shallow emotions (Frick, Ray, Thornton, \& Kahn, 2014). Measures of aggressive behaviours in childhood traditionally focus on overt aggression involving harm to others. Aggression measures can also include 'relational' aggression which by definition involves harm to the victim through purposeful damage to their relationships with others (Crick, 1996).

Whilst these externalising presentations are often studied separately, they are highly comorbid. Children with ODD and CD are thought to have much lower levels of empathy and increased rates of CU traits (de Wied et al., 2010). Comorbidity between ADHD and ODD is estimated to be $60 \%$ (APA, 2013) and comorbidity between ADHD and CD is 16-20\% with higher rates of comorbidity in boys than girls (Biederman et al., 2002).

\section{Facial Emotion Recognition and Externalising Behaviours}

Research has found that ER deficits are present in adolescent antisocial populations including those who present with CD and psychopathic traits (Fairchild, Stobbe, Van Goozen, Calder, \& Goodyer, 2010; Fairchild, Van Goozen, Calder, Stollery, \& Goodyer, 2009) and young offenders (Bowen, Morgan, Moore, \& van Goozen, 2014). Dawel et al. (2012) conducted a meta-analysis and found that psychopathy in adults and older children 
was associated with impairments in ER (vocal and facial) across positive and negative emotions. Their review suggested a generalised difficulty rather than one specific to particular emotions. It is noted that this study was limited in that none of the studies included in the meta-analysis focused exclusively on children exclusively ( 6 of the 26 studies included pre-adolescent children, but these samples also included adolescents). Also, the Dawel et al. paper did not present any data regarding hyperactivity or ADHD studies.

Bons et al. (2013) conducted a review of empathy in CD and Autism, including a synthesis of findings regarding ER in both diagnostic groups. They found mixed results in the seven studies which examined individuals with $\mathrm{CD}$, with four studies finding most pronounced difficulties with recognising negative emotions (fear, anger and disgust) and three studies reporting no difficulty. They also reported inconsistent results regarding a link between CU traits and the recognition of sad faces. Again, there was no inclusion of studies of ER in hyperactive or ADHD samples, and the studies included mainly focused on older children and adolescents.

Collin, Bindra, Raju, Gillberg, \& Minnis (2013) conducted a systematic review of FER studies across a wide range of psychiatric conditions throughout older childhood and adolescence (schizophrenia/psychosis, mood disorders, anxiety disorders, eating disorders, ADHD and CD). They concluded that all disorders have some association with FER difficulties but the evidence was too preliminary to draw any strong conclusions contrasting disorders. However, due to ER being a potential focus for early intervention, there has been a number of studies in younger children since that time.

Various theories relating to externalising behaviour problems propose a role for ER. Crick and Dodge (1994) proposed that individuals with aggression misinterpret ambiguous social cues as threatening and are therefore hypersensitive to emotions such as anger. Dadds, 
Jambrak, Pasalich, Hawes and Brennan (2011) have argued that deficits in FER in CP and $\mathrm{CU}$ populations may reflect general deficits in attention to social-emotional stimuli. Their argument follows previous findings that instructing children with high CU behaviours to look at the eye region reduces FER difficulties (Dadds, Masry, Wimalaweera, \& Guastella, 2008). Reduced amygdala activation has been found during the processing of fearful facial expressions in youth with disruptive/oppositional behaviours (Marsh et al., 2008) and boys with CU traits (Jones, Laurens, Herba, Barker, \& Viding, 2009), leading to theories that oppositional or CU children are 'under-reactive' to fear-related stimuli, decreasing the likelihood of them being able to inhibit aggression in the face of distress cues (Blair et al., 2014). In terms of attention/hyperactivity, ADHD is typically associated with a range of difficulties which may account for difficulties with ER such as reduced global cognitive ability (Frazier, Demaree, \& Youngstrom, 2004), difficulties in executive functioning such as response inhibition and working memory (Willcutt, Sonuga-Barke, Nigg, \& Sergeant, 2008) and attention difficulties. These difficulties have been suggested to affect children's ability to attend to, and therefore learn about facial emotions (Kats-Gold, Besser, \& Priel, 2007).

\section{Rationale and Aims of the Current Systematic Review}

In summary, ER is a crucial skill which we begin to learn at a young age and has been linked to a number of abilities and difficulties throughout the lifespan. However, research on the link between ER and externalising problems has tended to focus on adolescents-only or mixed child and adolescent samples, and so has not been developmentally sensitive given the neural changes that occur from childhood to adolescence. Hence, no clear conclusions have been drawn thus far about younger children, and thus whether there is evidence for intervening in FER abilities in specific younger age externalising behaviour groups. Systematic consideration of the findings across the various externalising categories (ADHD, $\mathrm{CP}$, Aggression and CU traits) simultaneously in studies exclusively looking at pre- 
adolescent children will offer an important contribution to the literature. Thus, the aim of this review is to systematically appraise the nature of the relationship between FER and externalising problems in young children, age 12 and under. It aims to ask, firstly, whether there is evidence for FER problems across externalising behaviour domains in pre-adolescent children, and if so, are specific emotions implicated? Secondly, is there evidence for specific patterns of FER problems in the different domains of externalising behaviours (ADHD, CP, CU traits and aggression)? Consideration of these questions will lead to a discussion about the implications for emotion-based interventions and future research.

\section{Methods}

\section{Search Strategy}

A systematic search of Psychinfo, Medline, Scopus and Web of Science was conducted to cover a broad range of psychological and social science journals. The search covered both English and American forms in the format: emotion recognition (emotion recog* or emotion recognition as a topic) AND Children (paediat*, preschool, infan*, kid, toddler, girl OR boy). Figure 1 provides the search process based on Preferred Reporting Items for Systematic Reviews and Meta Analyses (PRISMA) guidelines (Moher, Liberati, Tetzlaff, Altman, \& PRISMA Group, 2009). Studies were excluded for the following reasons: The article was not published in a peer-reviewed journal; it was not written in English; exclusively non-human populations were examined; only adults or children over 12 years old were examined or if data for children age 12 and under was not reported separately; all participants had a diagnosis of Autism, an Intellectual Disability (ID), or had specific health conditions or sensory difficulties (e.g., hearing or vision); an ecologically valid measure of FER was not used (e.g., vocal and scenario-based ER, non-photographic stimuli, or self, teacher or parent reports of emotion recognition); and a validated measure of externalising 
behaviour was not used. The decision not to include Autism-only or ID-only samples, in spite of externalising behaviours being prevalent in these groups, was to reduce noise in the data given the different aetiological processes in these groups (particularly in terms of genetics) compared to non-Autism/ID populations.

Where titles or abstracts did not contain this information, papers were included in the next stage of sifting. At the eligibility stage, 21 papers were excluded due to the age of the participants, 7 due to the ER task not specifically assessing FER of photographic faces, 3 did not use a validated measure of externalising behaviour or were self-report, 2 were not in peer review journals, and 3 did not report FER accuracy separately from other skills. The remaining studies were read in full, and the references were examined for further articles. Ultimately 16 papers were included in the review. Due to the specific aim of the review to focus on pre-adolescent children only, it was noted that several seminal papers in the area of emotion recognition and externalising behaviour difficulties were excluded due to including both younger children and adolescents (e.g., Blair, Colledge, Murray \& Mitchell, 2001; Cadesky, Mota \& Schachar, 2000; Dadds, Jambrak, Pasalich, Hawes \& Brennan, 2011).

\section{Results}

\section{Sample Characteristics and Design of Selected Studies}

Table 1 summarises the sample characteristics and findings of the selected studies. The 16 studies included 12611 children with sample sizes ranging from 48 to 6832 . All the studies provided child age ranges, and most provided information about gender. Just over half provided some description of the socio-economic status of the sample, and half of the studies provided information about the ethnicity of the sample. The studies were conducted in 9 different countries ( 7 out of the 16 were conducted in North America). 
Sixty-nine percent of studies were cross-sectional, and 19\% were longitudinal. Six included a control sample which ranged from 17 to 61 in size. Whilst all studies examined evidence for links between FER and externalising behaviours (through correlational or groupcomparison designs), this was not the primary objective for 5 studies.

\section{Analysis and Synthesis of Findings across Externalising Behaviour Groups}

Emotions Measured - Although not all studies reported emotions individually, happiness was tested most frequently by all 16 studies and sadness was tested by 15 , shortly followed by anger which was tested by 14 studies, and fear which was tested by 12 . Disgust, surprise and neutral were tested 6, 5 and 4 times respectively, and there were few significant results for these emotions. Seven of the 16 studies reported emotion findings separately by emotion, whereas 9 studies grouped performance across emotion types.

Publication bias - Five of the 16 studies did not report any significant findings and for only one of those, FER was not the primary focus. Despite the presentation of non-significant findings, publication bias cannot be ruled out as having exaggerated the pattern of significant findings.

Stimulus - Four of the studies used child faces as opposed to adult faces in the FER task, and only one of those (Bedford et al., 2017) found any evidence for an association between FER and externalising behaviour, whereas 10 of the 12 studies which used adult faces $(83 \%)$ found significant differences. None of the studies compared child and adult stimulus faces.

Sample Population - Of the 7 studies which used population or community samples, 3 (43\%) found evidence for a significant relationship between externalising behaviour and FER performance (through group or correlational analyses). Of the 9 studies which used samples 
that included children with known behavioural difficulties (e.g., clinic samples or behaviour problem programme samples) the figure was $89 \%$. The different pattern in findings depending on sample type suggests that some community samples might have too few children with high levels of externalising problems for effects to be evident. The impact of sample age range on key findings was also considered. Fourteen out of the 16 studies could be separated into younger (children aged 7 and under) and older samples (children aged 712). $66 \%$ of the younger sample studies found a significant relationship between externalising behaviour and FER performance (through group or correlational analyses); a similar proportion was found in the older sample studies (75\%). Thus, this analysis indicates that age range of the sample does not appear to impact upon whether or not there is evidence for FER problems in externalising behaviour groups.

\section{Externalising Behaviour and Emotion Recognition}

Eleven of the 16 studies (69\%) found a significant statistical result to suggest that an externalising behaviour construct was related to some aspect of FER performance. As a percentage of the number of studies for which it was tested and reported separately, there was variance in findings dependent on emotion type.

Fear - Externalising problems were related to poorer FER performance for fear in three $(60 \%)$ of the five studies which tested and reported it individually (Boakes et al., 2008; Kimonis et al., 2016; White et al., 2016). All of the studies with significant findings utilised samples of children with known behavioural difficulties.

Sadness - Externalising problems were related to poorer FER performance for sadness in three $(50 \%)$ of the six studies which tested and reported it individually (Kimonis et al., 2016; Pelc et al., 2006; Woodworth \& Waschbusch, 2008). All of the studies with significant findings utilised samples of children with known behavioural difficulties. 
Happiness - Higher rates of externalising problems were related to poorer FER performance for happiness in three (43\%) of the seven studies which tested and reported it individually (Chronaki et al., 2015; Kimonis et al., 2016; Rehder et al., 2017). Of these studies Rehder et al. (2017) was the only one which did not use a sample of children with known behavioural difficulties, they used a birth cohort with a sample size that was large enough to detect a significant, yet small, effect.

Anger - Externalising problems were related to poorer FER performance for anger in three of the seven (43\%) studies which tested and reported it individually (Chronaki et al., 2015; Kimonis et al., 2016; Pelc et al., 2006). All of the studies which found significant findings utilised samples of children with known behavioural difficulties.

Disgust - Externalising problems were related to poorer FER performance for disgust in one of the three studies (33\%) which tested and reported it individually (Boakes et al., 2008). This study used a sample of children with diagnoses of ADHD.

Neutral - One study tested and reported neutral faces individually (Chronaki et al., 2015) and used a sample of children with known behavioural problems, but did not find a significant difference between children with and without externalising problems.

Surprise - Externalising problems were not related to poorer FER performance for surprise in any of the three studies which tested and reported it individually. These studies used a mixture of $\mathrm{CP}$ and $\mathrm{ADHD}$ presentations in their samples.

Grouped FER Performance - Nine out of 16 studies analysed overall FER performance (i.e., combining ER accuracy across multiple emotions). Four (44\%) found evidence to suggest a link between externalising behaviour problems and ER (Bedford et al., 2017; Corbett \& Glidden, 2000; Kats-Gold et al., 2007; Martin et al., 2015). Of those, 2 used 
samples of children with known behavioural problems (Corbett \& Glidden, 2000; Kats-Gold et al., 2007). Of the 7 studies which analysed overall FER performance and did not find any significant findings, all but one (Shapiro et al., 1993) used community samples.

In summary, when studies test and report emotions individually, a link between happiness, anger, fear and sadness has been found with externalising problems an average of $49 \%$ of the time that they are tested. There is less evidence for relative problems recognising neutral, surprise and disgust; however very few studies have considered externalising behaviour in relation to these more complex emotional expressions.

\section{Analysis and Synthesis of Findings in Specific Externalising Behaviour Groups}

Hyperactivity/ADHD - Seven of the 16 studies (43.75\%) considered ADHD or inattention or hyperactivity in relation to FER (Boakes et al., 2008; Chronaki et al., 2015; Corbett \& Glidden, 2000; Kats-Gold et al., 2007; Martin et al., 2015; Pelc et al., 2006; Shapiro et al., 1993) and of these, 6 (86\%) found some evidence of FER problems. In samples including clinical cases, the specific nature of the FER problems differed: Chronaki, et al. (2015) found that hyperactivity was related to greater difficulty recognising happiness and anger; Boakes et al. (2008) found that both inattention and hyperactivity were significantly related to difficulty recognising disgust and fear; and Pelc et al. (2006) found that an ADHD diagnosis was significantly related to greater difficulty recognising sadness and anger. Corbett \& Glidden (2000), Kats-Gold et al. (2007) and Martin et al. (2015) grouped the FER findings and reported evidence of difficulty with FER in ADHD. In combination, these findings do not provide any evidence for difficulty with specific emotions in ADHD, however, non-consistent findings could be explained by large differences in study methods (e.g., emotion stimuli used, age and gender sample characteristics). In summary, the 
majority of published studies have found evidence for ADHD (or inattention/hyperactivity) being related to impaired performance in FER tasks. However, the exact nature of the FER difficulties is difficult to summarise, most probably as a result of methodological differences between studies.

Callous Unemotional traits - Six of the 16 studies (38\%) considered CU traits (Bedford et al., 2017; Kimonis et al., 2016; Rehder et al., 2017; Sharp et al., 2015; White et al., 2016; Woodworth \& Waschbusch, 2008). Of these, five (83\%) found evidence of CU traits being related to impaired performance on FER tasks. Of the studies which used samples of children with known behavioural problems, Kimonis et al. (2016) found a significant association between CU traits and difficulty recognising happiness, sadness, anger and fear. White et al. (2016) found that low levels of concern (considered by the author as a developmental manifestation of CU traits) were associated with difficulty recognising fear. Both Kimonis et al. and White et al. used large samples with a mix of boys and girls. However, Woodworth \& Waschbusch (2008), who found that CU traits were associated with difficulty recognising sadness, used a smaller sample with less girls. Two of the studies which found a significant association used community samples. Rehder et al. (2017) found a significant association between CU traits (and CP) and difficulty recognising happiness, whilst Bedford et al. (2017) tested happiness, sadness, anger and fear, and found that when grouped, impaired FER was associated with CU traits. Sharp et al. (2015) was the only study which measured CU traits but did not find an association with FER. They used a community sample in the Netherlands, and importantly, the FER stimulus was only the eye region, not the whole face. In summary, the findings suggest evidence for ER impairments in those with CU traits, but there is no consistent pattern in regards to whether these impairments are global (i.e., across emotional expressions) or specific. 
Conduct Problems - Three of the 16 studies (19\%) measured CP and all three (100\%) found a significant relationship between CP and FER performance (through group or correlational analyses). Rehder et al. (2017) found that CP was related to greater difficulty recognising happy faces, whereas Woodworth \& Waschbusch (2008) found that children with CP traits had greater difficulty recognising sadness than the control group. Chronaki et al. (2015) found no effect for sad or neutral faces, but hyperactivity and CP were linked to greater difficulty recognising happy and angry faces. In subsequent regression analyses (controlling for each symptom domain), Chronaki et al. found that it was hyperactivity, not CP, that better accounted for poorer FER performance. Woodworth \& Waschbusch (2008) controlled for ADHD symptoms but Rehder et al. (2017) did not, so it is not clear to what extent hyperactivity difficulties may account for these correlations. In summary, there are few studies that have considered CP and FER, and although all studies report FER deficits in CP, there is inconsistent evidence regarding specific emotion impairments.

Aggression and Externalising Behaviours - Two of the 16 studies (13\%) measured aggression. These studies did not find a significant relationship between FER performance and aggression (Liao et al., 2014; Parker et al., 2013). They used community samples and a mixture of boys and girls. Furthermore, both studies had relatively small sample sizes. Another study looked at internalising vs externalising (Rosenberg-Kima \& Sadeh, 2010) and did not find any significant associations but also used a small population sample. All three of these studies grouped FER. These findings do not suggest a strong link between FER difficulties and aggression or non-specific externalising presentations in the general population. 


\section{Discussion}

This review met the original aims to systematically appraise the nature of the association between FER and externalising problems in children. Specifically, we aimed to firstly investigate whether there is evidence for FER problems across externalising behaviour domains in pre-adolescent children (age 12 and under), and if so, which specific emotions are implicated. Secondly, we considered whether there is evidence for specific patterns of FER problems in the different domains of externalising behaviours (ADHD, CP, CU traits and aggression).

\section{Summary across Externalising Behaviour Groups}

This systematic review found evidence for FER skill deficits across pre-adolescent children presenting with externalising behaviours, with insufficient evidence to suggest a clear deficit in relation to any specific emotions. Eleven out of the 16 studies identified found evidence for FER performance being implicated in externalising behaviour problems. Associations between externalising behaviours and FER were less evident in community samples than in samples of children that included those with known behavioural problems (e.g., clinically-referred samples). Of the studies that considered the different emotions individually, a link between externalising behaviour and recognising happiness, anger, fear or sadness was identified approximately $50 \%$ of the time. There was less evidence for any link between externalising behaviour and relative problems recognising more complex emotions (e.g., neutral, surprise and disgust), although these complex emotions were studied less frequently. Of note, the stimuli for FER studies varied across studies (e.g., child or adult faces) and whilst this variation could have impacted upon the results, the data presented here is too limited to draw any firm conclusions. 


\section{Summary of Specific Externalising Behaviour Groups}

Although not fully conclusive, the data suggests that groups of children with clinical levels of hyperactivity or ADHD symptomatology are likely to have difficulties with FER. No clear pattern was identified linking ADHD to specific emotion expression deficits. These findings are in line with previous suggestions that the symptoms of ADHD, such as not properly attending to stimuli and executive function difficulties, might impact upon the development of their emotional knowledge generally (Frazier et al., 2004; Willcutt et al., 2008; Kats-Gold et al., 2007).

Similarly, the data suggests a generalised difficulty with FER for children with high levels of CU traits. This finding supports Dadds et al.'s (2011) argument for general deficits in attention to social-emotional stimuli for children with CP and CU traits. Specifically, they suggested that these children may pay less attention to eyes, hence leading to generalised FER deficits. Interestingly, the only CU study reviewed that did not find an effect of CU traits on ER (Sharp et al., 2015) used stimuli that only included the eye region, and so would have aided the participants in attending to this area. In addition, in those studies measuring ER in CU children, there were no fear-specific deficit trends suggestive, and so the studies reviewed do not support the theory of amygdala hyposensitivity in CU children (as suggested by Blair et al., 2014).

There were relatively few studies that studied FER in relation to CP. Although all of the studies identified found evidence to suggest FER deficits in CP, there was no consistent evidence regarding specific emotional deficits. One study (Chronaki et al., 2015) suggests that the association between $\mathrm{CP}$ and FER in younger children may be accounted for by hyperactivity and attention difficulties, yet few CP (or indeed CU) studies have controlled for the comorbid presence of ADHD. Given the high levels of comorbidity, it is plausible that this explanation applies to a range of externalising problems and requires further research. 


\section{Limitations}

First, there is a very real risk that publication bias might have meant that studies finding a non-significant association between FER and externalising behaviours have not been published. Thus, the report of significant findings presented here (which already include several studies finding non-significant relationships between externalising behaviour and FER performance) may be an exaggeration of reality. Second, whilst this review is crucial in taking the first step to systematically appraise and collate the available research regarding FER in pre-adolescent children with externalising behaviours, the generalisability of these findings is limited. The country under study varied significantly, and therefore there are several relevant cultural factors which are beyond the scope of this review. In addition, whilst several studies sampled relatively equal numbers of boys and girls, some were either mostly or only boys, and so no conclusions could be drawn regarding gender. Third, as already discussed, the studies used a variety of methods in terms of sample characteristics and measurements, causing problems drawing firm conclusions. Fourth, the labelling of prototypical emotions is the most frequently researched aspect of ER and the easiest to assess, however it is less ecologically valid than assessing labelling of non-prototypical emotions (Castro et al., 2016). Fifth, this systematic review has not explored the role of the child's early life and home environment which is known to affect ER and externalising behaviours (e.g., Brownell, Svetlova, Anderson, Nichols, \& Drummond, 2013; Murray \& Farrington, 2010). Experiences of abuse and neglect have been found to differentially affect FER (Pollak, Cicchetti, Hornung, \& Reed, 2000; Pollak, Messner, Kistler, \& Cohn, 2009; Pollak \& Kistler, 2002) as has harsh parenting (Jaffee, 2017), maternal depressive symptoms (Kujawa et al., 2014) and attachment insecurity (Cooke, Stuart-Parrigon, Movahed-Abtahi, Koehn, \& Kerns, 2016). Early environment factors (largely unmeasured in the studies 
chosen) might be more predictive of emotional deficits than behavioural profiles, and thus account for the inconsistency in findings across the included studies.

\section{Future Research}

This systematic review has highlighted a number of recommendations for future research. Firstly, our findings suggest that FER problems are unlikely to be highly relevant to mild or commonly occurring levels of externalising behaviour, and so future research investigating FER and externalising behaviours should utilise samples enriched with higher levels of psychopathology. In addition, samples should contain a mixture of boys and girls with an appropriate control sample. Bedford et al. (2017) found that ER predicted later CU behaviours. However, very few studies included in this review studied longitudinal effects of FER performance, therefore future research would ideally be prospective or longitudinal in order to examine any causal links with FER difficulties and later behavioural problems. Thus far, much of the research into ADHD and CP or CU traits is conducted separately. Given the initial evidence that attention difficulties or hyperactivity may account for association between $\mathrm{CP}$ and FER, further research is needed that investigates the independent association of $\mathrm{CP}$ or $\mathrm{CU}$ presentations and inattention or hyperactivity.

Many of the studies examined did not control for likely variables that might impact upon a child's performance on FER tasks of children in younger age groups (most notably verbal ability or IQ). Therefore, future research should include verbal ability or IQ as a covariate. Some of the inconsistencies in findings covered in this review might be due to the broad measures of FER used assessing multiple underlying processes. It might be that specific manifestations of behavioural problems are linked to more specific aspects of emotional or empathic function. For example, the extent to which attention is focused on the eyes appears to be predictive of FER performance (Dadds et al., 2008) in some externalising groups. One variable not considered in the studies included in this review is children's basic 
cognitive and affective 'Theory of mind' (ToM) abilities (i.e., the ability to see other people as having distinct thoughts and emotions to oneself). ToM is at a key stage of development in younger children (Guilé, 2014), particularly between the ages of 4 and 6 (Astington \& Gopnik, 1991; Miller, 2009). Delays in ToM development might impact upon the levels of attention that children give to the emotional expressions of others, thus impacting upon their FER development. Further research should attempt to disentangle which aspects of cognitive and affective empathic function most reliably predict different behavioural manifestations.

Finally, external validity and clinical application should be considered carefully when selecting stimulus for future FER research. One second clips have been found to provide more robust results (Kimonis et al., 2016) and researchers should test a wide range of emotions (reporting their findings individually) displaying a range of intensities. In addition, it would be beneficial to study the extent to which the ability to recognise child and adult stimulus faces differ in children with externalising behaviours.

\section{Clinical Implications}

The overall findings suggest that many (but not all) children with significant externalising problems have problems with FER, and thus it might form part of an important pathway to externalising problems in some children. However, as noted, prospective longitudinal designs controlling for relevant confounding factors would need to confirm the role of FER difficulties in the development of externalising behaviours. If FER difficulties are involved in the pathway to behavioural difficulties, given the long-term implications of externalising behaviours, many children at risk of later problems would likely benefit from constructive assessment and support with their emotional and relational skills (including FER) early in life, rather than only their academic skills. Services would also need to be aware when assessing children that the evidence base does not show clear associations 
between specific skill deficits and clinical diagnosis, and therefore prescribed interventions will need to be informed by more thorough individualised assessment and formulation.

There has been mixed findings about whether emotion training interventions improve behaviour in children and adolescents. For example, Dadds and colleagues found that emotion training did not generally improve $\mathrm{CP}$ compared to a family intervention in a group of children and adolescents with a mixture of emotional and behavioural difficulties; however, children with CU traits specifically did evidence lower levels of $\mathrm{CP}$ when receiving the emotion training (Dadds, Cauchi, Wimalaweera, Hawes, \& Brennan, 2012). Hubble, Moore, Bowen \& van Goozen (2015) found that juvenile offenders had improved criminal outcomes following an emotion recognition training intervention compared to controls; however, the control group did not receive a comparable intervention without emotion training, meaning that firm conclusions could not be drawn about the impact of emotion training sepcifically. This review indicates that it would be worthwhile to research whether adapting such training to younger populations is of clinical benefit for children with externalising behaviours, although rigorous randomised control trials would be needed to properly evaluate the impact of emotion training specifically. Emotion-based interventions are a particularly neglected area in the treatment of ADHD-related problems; in spite of this review not being conclusive about causality, it would nevertheless support preliminary research about the impact of such interventions in ADHD groups. Given the evidence that FER develops in families where there are frequent displays of positive emotions and fewer displays of negative emotion (Denham \& Kochanoff, 2002; Laible, 2011; McElwain et al., 2007), then whole family approaches that include emotional learning strategies might be particularly relevant when clinical levels of externalising behaviours are present (e.g., Mentalization Based Treatment for Families; Asen \& Fonagy, 2012). 


\section{Conclusions}

Overall, there was the strongest evidence for significant findings regarding FER problems in ADHD, CU and CP presentations, and in samples of children with higher levels of externalising problems rather than in community samples. Within the various externalising behaviour groups there was no clear evidence for specific emotion deficits, which is consistent with other reviews in older children and adults (Dawel et al., 2012; Bons et al., 2013; and Collin et al., 2013).

\section{References}

American Psychiatric Association. (2013). Diagnostic and Statistical Manual of Mental Disorders. American Psychiatric Association.

Asen, E., \& Fonagy, P. (2012). Mentalization-based Therapeutic Interventions for Families. Journal of Family Therapy, 34(4), 347-370.

Astington, J. W., \& Gopnik, A. (1991). Theoretical explanations of children's understanding of the mind. British Journal of Developmental Psychology, 9(1), 7-31.

Bedford, R., Wagner, N. J., Rehder, P. D., Propper, C., Willoughby, M. T., \& Mills-Koonce, R. W. (2017). The role of infants' mother-directed gaze, maternal sensitivity, and emotion recognition in childhood callous unemotional behaviours. European Child \& Adolescent Psychiatry, 26(8), 947-956.

Biederman, J., Mick, E., Faraone, S. V., Braaten, E., Doyle, A., Spencer, T., ... Johnson, M. A. (2002). Influence of gender on attention deficit hyperactivity disorder in children referred to a psychiatric clinic. The American Journal of Psychiatry, 159(1), 36-42.

Blair, R. J., Colledge, E., Murray, L., \& Mitchell, D. G. (2001). A selective impairment in the 
processing of sad and fearful expressions in children with psychopathic tendencies. Journal of Abnormal Child Psychology, 29, 491-498.

Blair, R. J. R., Leibenluft, E., \& Pine, D. S. (2014). Conduct Disorder and CallousUnemotional Traits in Youth. New England Journal of Medicine, 371(23), 2207-2216.

Boakes, J., Chapman, E., Houghton, S., \& West, J. (2008). Facial affect interpretation in boys with attention deficit/hyperactivity disorder. Child Neuropsychology, 14(1), 82-96.

Bons, D., van den Broek, E., Scheepers, F., Herpers, P., Rommelse, N., Buitelaaar, J. K., \& Buitelaaar, J. K. (2013). Motor, Emotional, and Cognitive Empathy in Children and Adolescents with Autism Spectrum Disorder and Conduct Disorder. Journal of Abnormal Child Psychology, 41(3), 425-443.

Bowen, K. L., Morgan, J. E., Moore, S. C., \& van Goozen, S. H. M. (2014). Young Offenders' Emotion Recognition Dysfunction Across Emotion Intensities: Explaining Variation Using Psychopathic Traits, Conduct Disorder and Offense Severity. Journal of Psychopathology and Behavioral Assessment, 36(1), 60-73.

Brownell, C. A., Svetlova, M., Anderson, R., Nichols, S. R., \& Drummond, J. (2013). Socialization of Early Prosocial Behavior: Parents' Talk About Emotions is Associated With Sharing and Helping in Toddlers. Infancy, 18(1), 91-119.

Cadesky, E. B., Mota, V. L., \& Schachar, R. J., (2000). Beyond words: How do children with ADHD and/or conduct problems process nonverbal information about affect? Journal of American Academy of Child and Adolescent Psychiatry, 39, 1160-1167.

Camras, L. A., Ribordy, S., Hill, J., Martino, S., Spaccarelli, S., \& Stefani, R. (1988). Recognition and Posing of Emotional Expressions by Abused Children and Their Mothers. Developmental Psychology, 24(6), 776-781. 
Castro, V. L., Cheng, Y., Halberstadt, A. G., \& Gruhn, D. (2016). EUReKA! A Conceptual Model of Emotion Understanding. EMOTION REVIEW, 8(3), 258-268.

Chronaki, G., Garner, M., Hadwin, J. A., Thompson, M. J. J., Chin, C. Y., \& Sonuga-Barke, E. J. S. (2015). Emotion-recognition abilities and behavior problem dimensions in preschoolers: Evidence for a specific role for childhood hyperactivity. Child Neuropsychology, 21(1), 25-40.

Cicchetti, D. (2016). Socioemotional, Personality, and Biological Development: Illustrations from a Multilevel Developmental Psychopathology Perspective on Child Maltreatment. Annual Review of Psychology, 67(1), 187-211.

Collin, L., Bindra, J., Raju, M., Gillberg, C., \& Minnis, H. (2013). Facial emotion recognition in child psychiatry: Research in Developmental Disabilities, 34(5), 1505-1520.

Cooke, J. E., Stuart-Parrigon, K. L., Movahed-Abtahi, M., Koehn, A. J., \& Kerns, K. A. (2016). Children's emotion understanding and mother-child attachment: A metaanalysis. Emotion, 16(8), 1102-1106.

Corbett, B., \& Glidden, H. (2000). Processing affective stimuli in children with attentiondeficit hyperactivity disorder. Child Neuropsychology, 6(2), 144-155.

Crick, N. R. (1996). The role of overt aggression, relational aggression, and prosocial behavior in the prediction of children's future social adjustment. Child Development, 67(5), 2317-2327.

Crick, N. R., \& Dodge, K. A. (1994). A review and reformulation of social informationprocessing mechanisms in children's social adjustment. Psychological Bulletin, 115(1), $74-101$.

Dadds M. R., Cauchi A. J., Wimalaweera S, Hawes D. J., \& Brennan J. (2012). Outcomes, 
moderators, and mediators of empathic-emotion recognition training for complex conduct problems in childhood. Psychiatry Research, 199, 201-207.

Dadds, M. R., El Masry, Y., Wimalaweera, S., \& Guastella, A. J. (2008). Reduced eye gaze explains "fear blindness" in childhood psychopathic traits. Journal of the American Academy of Child and Adolescent Psychiatry, 47(4), 455-463.

Dadds, M. R., Jambrak, J., Pasalich, D., Hawes, D. J., \& Brennan, J. (2011). Impaired attention to the eyes of attachment figures and the developmental origins of psychopathy. Journal of Child Psychology and Psychiatry, 52(3), 238-245.

Dawel, A., O’Kearney, R., McKone, E., \& Palermo, R. (2012).Not just fear and sadness: Meta-analytic evidence of pervasive emotion recognition deficits for facial and vocal expressions in psychopathy.Neuroscience \& Biobehavioral Reviews,36(10),2288-2304.

de Wied, M., Gispen-de Wied, C., \& van Boxtel, A. (2010). Empathy dysfunction in children and adolescents with disruptive behavior disorders. European Journal of Pharmacology, 626(1), 97-103.

Denham, S. A., Blair, K. A., DeMulder, E., Levitas, J., Sawyer, K., Auerbach-Major, S., \& Queenan, P. (2003). Preschool Emotional Competence: Pathway to Social Competence? Child Development, 74(1), 238-256.

Denham, S., \& Kochanoff, A. T. (2002). Parental Contributions to Preschoolers' Understanding of Emotion. Marriage \& Family Review, 34(3-4), 311-343.

Fairchild, G., Stobbe, Y., Van Goozen, S. H. M., Calder, A. J., \& Goodyer, I. M. (2010). Facial expression recognition, fear conditioning, and startle modulation in female subjects with conduct disorder. Biological Psychiatry, 68(3), 272-279.

Fairchild, G., Van Goozen, S. H. M., Calder, A. J., Stollery, S. J., \& Goodyer, I. M. (2009). 
Deficits in facial expression recognition in male adolescents with early-onset or adolescence-onset conduct disorder. Journal of Child Psychology and Psychiatry and Allied Disciplines, 50(5), 627-636.

Frazier, T. W., Demaree, H. A., \& Youngstrom, E. A. (2004). Meta-Analysis of Intellectual and Neuropsychological Test Performance in Attention-Deficit/Hyperactivity Disorder Neuropsychology, 18(3), 543-555.

Frick, P. J. (2012). Developmental Pathways to Conduct Disorder: Implications for Future Directions in Research, Assessment, and Treatment. Journal of Clinical Child \& Adolescent Psychology, 41(3), 378-389.

Frick, P. J., Ray, J. V, Thornton, L. C., \& Kahn, R. E. (2014). Can callous-unemotional traits enhance the understanding, diagnosis and treatment of serious conduct problems in children and adolescents? A comprehensive review.Psychological Bulletin, 140(1),1-57.

Frick, P. J., \& Viding, E. (2009). Antisocial behavior from a developmental psychopathology perspective. Development and Psychopathology, 21(04), 1111.

Frick, P. J., \& White, S. F. (2008). Research Review: The importance of callous-unemotional traits for developmental models of aggressive and antisocial behavior. Journal of Child Psychology and Psychiatry and Allied Disciplines, 49(4), 359-375.

Frith, C. (2009). Role of facial expressions in social interactions. Philosophical Transactions of the Royal Society of London. Series B, Biological Sciences, 364(1535), 3453-3458.

Guilé, J. M. (2014). Probabilistic Perception, Empathy, and Dynamic Homeostasis: Insights in Autism Spectrum Disorders and Conduct Disorders. Frontiers in Public Health,2,1-6.

Hare, R, D. (1991). The Hare Psychopathy Checklist-Revised (PCL-R). Toronto, Ontario, Canada: : Multi-Health Systems. 
Hubble, K., Bowen, K. L., Moore, S. C., \& van Goozen, S. H. M. (2015). Improving negative emotion recognition in young offenders reduces subsequent crime. PLOS ONE, 10(6).

Izard, C., Fine, S., Schultz, D., Mostow, A., Ackerman, B., \& Youngstrom, E. (2001). Emotion knowledge as a predictor of social behavior and academic competence in children at risk. Psychological Science, 12(1), 18-23.

Jaffee, S. R. (2017). Child maltreatment and risk for psychopathology in childhood and adulthood. Annual Review of Clinical Psychology, 13, 525-551.

Jones, A. P., Laurens, K. R., Herba, C. M., Barker, G. J., \& Viding, E. (2009). Amygdala Hypoactivity to Fearful Faces in Boys With Conduct Problems and CallousUnemotional Traits. American Journal of Psychiatry, 166(1), 95-102.

Kats-Gold, I., Besser, A., \& Priel, B. (2007). The role of simple emotion recognition skills among school aged boys at risk of ADHD. Journal of Abnormal Child Psychology, 35(3), 363-378.

Kimonis, E. R., Fanti, K. A., Anastassiou-Hadjicharalambous, X., Mertan, B., Goulter, N., \& Katsimicha, E. (2016). Can Callous-Unemotional Traits be Reliably Measured in Preschoolers? Journal of Abnormal Child Psychology, 44(4), 625-638.

Kujawa, A., Dougherty, L., Durbin, C. E., Laptook, R., Torpey, D., \& Klein, D. N. (2014). Emotion recognition in preschool children: Associations with maternal depression and early parenting. Development and Psychopathology, 26(1), 159-170.

Laible, D. (2011). Does It Matter if Preschool Children and Mothers Discuss Positive vs. Negative Events During Reminiscing? Links with Mother-reported Attachment, Family Emotional Climate, \&Socioemotional Development.Social Development,20(2),394-411.

Leibson, C. L., \& Hall Long, K. (2003). Economic Implications of Attention-Deficit 
Hyperactivity Disorder for Healthcare Systems.PharmacoEconomics,21(17),1239-1262.

Liao, Z., Li, Y., \& Su, Y. (2014). Emotion understanding and reconciliation in overt and relational conflict scenarios among preschoolers. International Journal of Behavioral Development, 38(2), 111-117.

Lorber, M. F. (2004). Psychophysiology of aggression, psychopathy, and conduct problems: A meta-analysis. Psychological Bulletin, 130(4), 531-552.

MacDonald, P. M., Kirkpatrick, S. W., \& Sullivan, L. A. (1996). Schematic drawings of facial expressions for emotion recognition and interpretation by preschool-aged children. Genetic, Social, and General Psychology Monographs, 122(4), 373-388.

Mannuzza, Salvatore Klein, R. G. (2000). Long-term prognosis in attentiondeficit/hyperactivity disorder. Child and Adolescent Psychiatric Clinics of North America, 9(3), 711-726.

Marsh, A. A., Finger, E. C., Mitchell, D. G. V., Reid, M. E., Sims, C., Kosson, D. S., ... Blair, R. J. R. (2008). Reduced Amygdala Response to Fearful Expressions in Children and Adolescents With Callous-Unemotional Traits and Disruptive Behavior Disorders. American Journal of Psychiatry, 165(6), 712-720.

Martin, J., Hamshere, M. L., Stergiakouli, E., O’Donovan, M. C., \& Thapar, A. (2015). Neurocognitive abilities in the general population and composite genetic risk scores for attention-deficit hyperactivity disorder. Journal of Child Psychology and Psychiatry, and Allied Disciplines, 56(6), 648-656.

McElwain, N. L., Halberstadt, A. G., \& Volling, B. L. (2007). Mother- and Father-Reported Reactions to Children's Negative Emotions: Relations to Young Children's Emotional Understanding and Friendship Quality. Child Development, 78(5), 1407. 
Miller, S. A. (2009). Children's understanding of second-order mental states. Psychological Bulletin, 135(5), 749-773.

Moher, D., Liberati, A., Tetzlaff, J., Altman, D. G., \& PRISMA Group. (2009). Preferred reporting items for systematic reviews and meta-analyses: the PRISMA statement. Annals of Internal Medicine, 151(4), 264-269, W64.

Murray, J., \& Farrington, D. P. (2010). Risk Factors for Conduct Disorder and Delinquency: Key Findings from Longitudinal Studies.The Canadian Journal of Psychiatry,55(10),633-642.

NICE. (2012). Methods for the development of NICE public health guidance (third edition ). National Institute of Health and Clinical Excellence, (September), 284.

Odgers, C. L., Caspi, A., Broadbent, J. M., Dickson, N., Hancox, R. J., Harrington, H., ... Moffitt, T. E. (2007). Prediction of Differential Adult Health Burden by Conduct Problem Subtypes in Males. Archives of General Psychiatry, 64(4), 476.

Parker, A. E., Mathis, E. T., \& Kupersmidt, J. B. (2013). How is this child feeling? Preschool-aged children's ability to recognize emotion in faces and body poses. Early Education and Development, 24(2), 188-211.

Pelc, K., Kornreich, C., Foisy, M.-L., \& Dan, B. (2006). Recognition of emotional facial expressions in attention-deficit hyperactivity disorder. Pediatric Neurology,35(2),93-97.

Pollak, S. D., Cicchetti, D., Hornung, K., \& Reed, A. (2000). Recognizing emotion in faces: Developmental effects of child abuse and neglect. Developmental Psychology,36(5), $679-688$.

Pollak, S. D., \& Kistler, D. J. (2002). Early experience is associated with the development of categorical representations for facial expressions of emotion. Proceedings of the 
National Academy of Sciences of the United States of America, 99(13), 9072-9076.

Pollak, S. D., Messner, M., Kistler, D. J., \& Cohn, J. F. (2009). Development of perceptual expertise in emotion recognition. Cognition, 110(2), 242-247.

Rehder, P. D., Mills-Koonce, W. R., Willoughby, M. T., Garrett-Peters, P., \& Wagner, N. J. (2017). Emotion recognition deficits among children with conduct problems and callous-unemotional behaviors. Early Childhood Research Quarterly, 41, 174-183.

Rodger, H., Vizioli, L., Ouyang, X., \& Caldara, R. (2015). Mapping the development of facial expression recognition. Developmental Science, 18(6), 926-939.

Rosenberg-Kima, R. B., \& Sadeh, A. (2010). Attention, response inhibition, and faceinformation processing in children: The role of task characteristics, age, and gender. Child Neuropsychology, 16(4), 388-404.

Russell, J. A., \& Widen, S. C. (2002). A Label Superiority Effect in Children's Categorization of Facial Expressions. Social Development, 11(1), 30-52.

Saarni, C. (1999). The development of emotional competence. Guilford Press.

Schultz, D., Izard, C. E., \& Ackerman, B. P. (2000). Children's Anger Attribution Bias: Relations to Family Environment and Social Adjustment. Social Development, 9(3), $284-301$.

Shapiro, E. G., Hughes, S. J., August, G. J., \& Bloomquist, M. L. (1993). Processing of emotional information in children with attention-deficit hyperactivity disorder. Developmental Neuropsychology, 9(3-4), 207-224.

Sharp, C., Vanwoerden, S., Van Baardewijk, Y., Tackett, J. L., \& Stegge J. L.; (2015). Callous-unemotional traits are associated with deficits in recognizing complex emotions in preadolescent children. Journal of Personality Disorders, 29(3), 347-359. 
Sirriyeh, R., Lawton, R., Gardner, P., \& Armitage, G. (2012). Reviewing studies with diverse designs: the development and evaluation of a new tool. Journal of Evaluation in Clinical Practice, 18(4), 746-752.

White, S. F., Briggs-Gowan, M. J., Voss, J. L., Petitclerc, A., McCarthy, K., Blair, R. J. R., \& Wakschlag, L. S. (2016). Can the fear recognition deficits associated with callousunemotional traits be identified in early childhood? Journal of Clinical and Experimental Neuropsychology, 38(6), 672-684.

Wilens, T. E., \& Spencer, T. J. (2010). Understanding Attention-Deficit/Hyperactivity Disorder from Childhood to Adulthood. Postgraduate Medicine, 122(5), 97-109.

Willcutt, E. G., Sonuga-Barke, E. J. S., Nigg, J. T., \& Sergeant, J. A. (2008). Recent Developments in Neuropsychological Models of Childhood Psychiatric Disorders. In Biological Child Psychiatry (Vol. 24, pp. 195-226). Basel: KARGER.

Woodworth, M., \& Waschbusch, D. (2008).Emotional processing in children with conduct problems\&callous/unemotional traits.Child:Care,Health \& Development,34(2),234-244. 


\section{Tables and Figures}

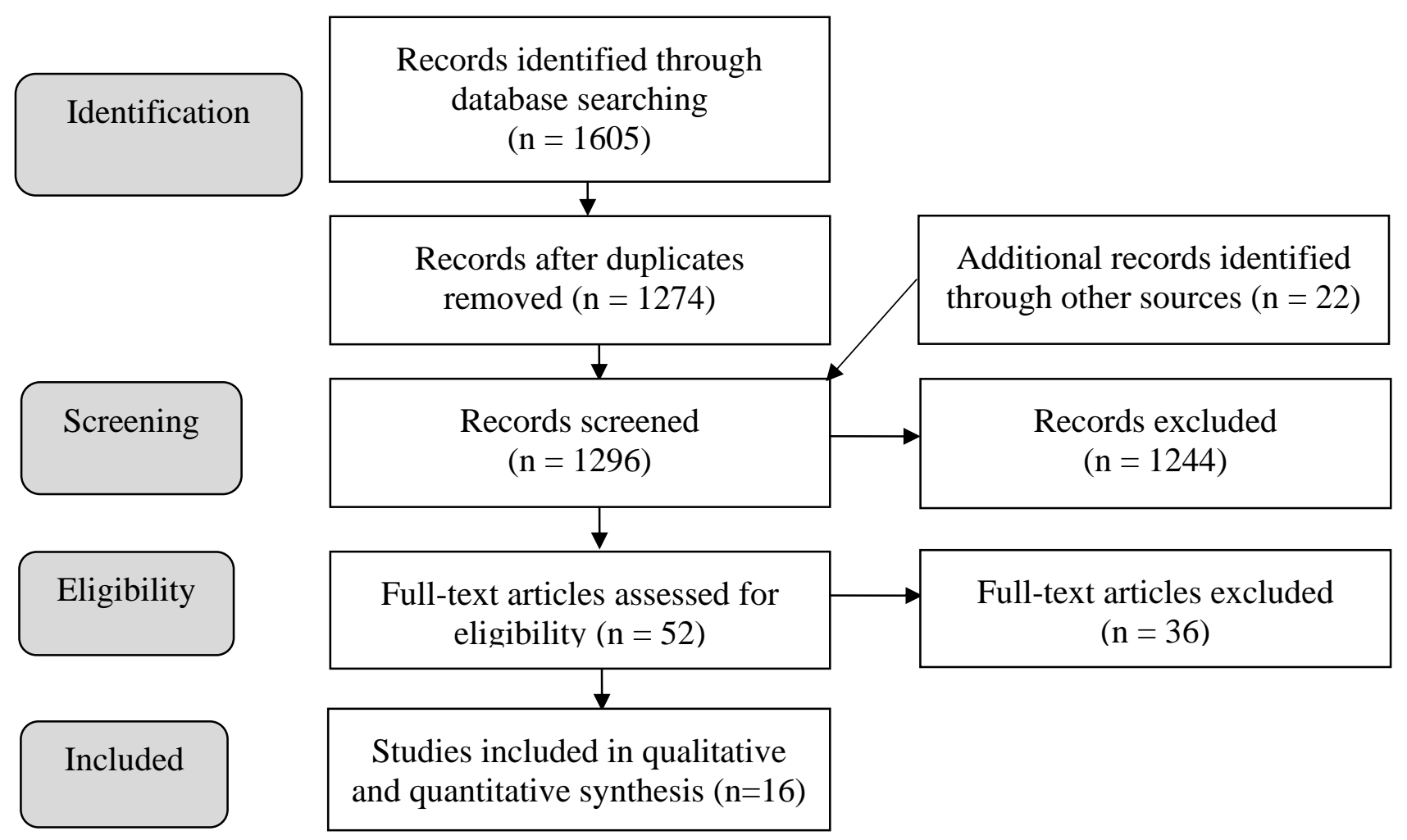

Figure 1. PRISMA Flow Diagram Demonstrating Systematic Review Procedure. 
Table 1. Sample characteristics, measures, control variables and findings for the studies included in this review.

\begin{tabular}{|c|c|c|c|c|c|c|}
\hline Paper & Sample Characteristics & $\begin{array}{l}\text { Sample Size, Age } \\
\text { Range (Years) and } \\
\% \text { Female }\end{array}$ & $\begin{array}{l}\text { Type of Externalising } \\
\text { Problem and Measure }\end{array}$ & $\begin{array}{l}\text { Measure of FER and } \\
\text { Stimulus }\end{array}$ & Control variables & $\begin{array}{l}\text { Findings and Emotions } \\
\text { Tested } \\
\text { (underlined if sig. } \\
\text { impairment identified) }\end{array}$ \\
\hline $\begin{array}{l}\text { Bedford et al. } \\
(2017)\end{array}$ & $\begin{array}{l}\text { >USA: Community sample } \\
\text { SES: } 53 \% \text { on low income } \\
\text { Ethnicity: } 57 \% \text { African American, } 43 \% \text { European } \\
\text { American }\end{array}$ & $\begin{array}{l}\mathrm{N}=206 \\
\text { Age: } 6-7 \\
\text { Female: } \text { not } \\
\text { reported }\end{array}$ & $\begin{array}{l}\text { CU traits } \\
\text { Measure: ICU age } 7\end{array}$ & $\begin{array}{l}\text { Measure: Facial } \\
\text { expressions subscale of } \\
\text { the ACES } \\
\text { Stimulus: Child }\end{array}$ & $\begin{array}{l}\text { Sex, race, poverty } \\
\text { status, earlier CU } \\
\text { behaviours. }\end{array}$ & $\begin{array}{l}\text { Grouped - Happy, Sad, } \\
\text { Anger and Fear (CU } \\
\text { traits) }\end{array}$ \\
\hline $\begin{array}{l}\text { Chronaki, et } \\
\text { al. (2015) }\end{array}$ & $\begin{array}{l}\text { >England: Nurseries and referrals for emotional or } \\
\text { behavioural difficulties } \\
\text { SES and Ethnicity not reported }\end{array}$ & $\begin{array}{l}N=57 \\
\text { Age: } 2-6 \\
\text { Female: } 58 \%\end{array}$ & $\begin{array}{l}\text { Hyperactivity \& CP } \\
\text { Measure: SDQ }\end{array}$ & $\begin{array}{l}\text { Measure: Ekman \& } \\
\text { Friesen's faces } \\
\text { Stimulus: Adult female, } \\
2 \text { intensities }\end{array}$ & $\begin{array}{l}\text { Gender, age, } \\
\text { voice/face } \\
\text { modality. }\end{array}$ & $\begin{array}{l}\frac{\text { Happy }}{\text { Sad }}(\text { Hyp \& CP) } \\
\frac{\text { Anger }}{\text { Neutral }}\end{array}$ \\
\hline $\begin{array}{l}\text { Kimonis et al. } \\
(2016)\end{array}$ & $\begin{array}{l}\text { >Cyprus: Mainstream and high-risk preschools } \\
\text { SES: In high risk group average family income was } \\
\text { lower (16,771 vs } 30,528 \text { Euros) } \\
\text { Ethnicity: Not reported }\end{array}$ & $\begin{array}{l}N=214 \\
\text { Age: } 3-6 \\
\text { Female: } 47 \%\end{array}$ & $\begin{array}{l}\text { CU traits, CP, } \\
\text { aggression } \\
\text { Measure: ICU, UNSW } \\
\text { CU scale, ECBI, PSBS- } \\
\text { T, APSD }\end{array}$ & $\begin{array}{l}\text { Measure: Dynamic } 1 \mathrm{~s} \\
\text { clips from MPAFC } \\
\text { database } \\
\text { Stimulus: Adult male \& } \\
\text { female }\end{array}$ & Sample, age, sex & $\begin{array}{l}\text { Happy (CU traits) } \\
\text { Sad (CU traits) } \\
\text { Anger (CU traits) } \\
\underline{\text { Fear (CU traits) }}\end{array}$ \\
\hline $\begin{array}{l}\text { Liao et al. } \\
\text { (2014) }\end{array}$ & $\begin{array}{l}\text { >China: Kindergartens in Beijing } \\
\text { SES and Ethnicity: Not reported }\end{array}$ & $\begin{array}{l}\mathrm{N}=47 \\
\text { Age: } 4-6 \\
\text { Female: } 51 \%\end{array}$ & $\begin{array}{l}\text { Aggression } \\
\text { Measure: CSBS-TF }\end{array}$ & $\begin{array}{l}\text { Measure: Adapted from } \\
\text { Denham \& Couchoud. } \\
\text { Stimulus: One intensity }\end{array}$ & Age, gender & $\begin{array}{l}\text { Grouped - Happy, Sad, } \\
\text { Disgust, Anger or Fear } \\
\text { (Aggression) }\end{array}$ \\
\hline $\begin{array}{l}\text { Martin et al. } \\
\text { (2015) }\end{array}$ & $\begin{array}{l}\text { >England: Longitudinal Study (ALSPAC) } \\
\text { SES and Ethnicity: Not reported }\end{array}$ & $\begin{array}{l}N=6832 \\
\text { Age: } 7-11 \\
\text { Female: } 49 \%\end{array}$ & $\begin{array}{l}\text { ADHD } \\
\text { Measure: DAWBA }\end{array}$ & $\begin{array}{l}\text { Measure: The faces } \\
\text { subtest of the DANVA } \\
\text { Stimulus: Two } \\
\text { intensities }\end{array}$ & $\begin{array}{l}\text { IQ, working } \\
\text { memory, Cognitive } \\
\text { inhibitory control }\end{array}$ & $\begin{array}{l}\text { Grouped - Happy, Sad, } \\
\text { Anger, Fear (ADHD) }\end{array}$ \\
\hline $\begin{array}{l}\text { Parker et al. } \\
\text { (2013) }\end{array}$ & $\begin{array}{l}\text { >USA: } 7 \text { child care centres } \\
\text { SES: average annual household income of } \$ 67,500 \\
\text { Ethnicity: } 63 \% \text { White, } 22 \% \text { African American, } 9 \% \\
\text { Asian American, } 13 \% \text { other }\end{array}$ & $\begin{array}{l}N=55 \\
\text { Age: } 3-6 \\
\text { Female: } 44 \%\end{array}$ & $\begin{array}{l}\text { Aggression } \\
\text { Measure: } \mathrm{CBCL}\end{array}$ & $\begin{array}{l}\text { Measure: CARE, coded } \\
\text { using the FACS \& the } \\
\text { ACES } \\
\text { Stimulus: Child - boys \& } \\
\text { girls (ethnicity matched) }\end{array}$ & Age & $\begin{array}{l}\text { Grouped - Happy, sad, } \\
\text { surprise, disgust, anger, } \\
\text { fear \& Neutral } \\
\text { (Aggression) }\end{array}$ \\
\hline $\begin{array}{l}\text { Rehder et al. } \\
\text { (2017) }\end{array}$ & $\begin{array}{l}\text { >USA: Birth cohort, over-sampling for poverty \& } \\
\text { ethnic minorities } \\
\text { SES: Rural poverty } \\
\text { Ethnicity: } 59 \% \text { European American; } 41 \% \text { African }\end{array}$ & $\begin{array}{l}N=761 \\
\text { Age: } 7-8 \\
\text { Female: } 51 \%\end{array}$ & $\begin{array}{l}\text { CP and CU traits } \\
\text { Measure: DBDRS \& } \\
\text { ICU }\end{array}$ & $\begin{array}{l}\text { Measure: ICE } \\
\text { Stimulus: Adults }-2 \\
\text { ethnicities, } 7 \text { intensities }\end{array}$ & $\begin{array}{l}\text { Gender, ethnicity, } \\
\text { family income, } \\
\text { caregiver's } \\
\text { education and }\end{array}$ & $\begin{array}{l}\text { Happy (CP \& CU traits) } \\
\text { Sad } \\
\text { Surprise } \\
\text { Anger }\end{array}$ \\
\hline $\begin{array}{l}\text { Rosenberg- } \\
\text { Kima \& Sadeh } \\
(2010)\end{array}$ & $\begin{array}{l}\text { American } \\
\text { >Israel: School children } \\
\text { SES: Most parents employed and well educated } \\
\text { Ethnicity: In } 25 \% \text { of families, } 1 \text { or both parents } \\
\text { immigrated }\end{array}$ & $\begin{array}{l}\mathrm{N}=134 \\
\text { Age: } 7-12 \\
\text { Female: } 60 \%\end{array}$ & $\begin{array}{l}\text { Externalising \& } \\
\text { internalising } \\
\text { Measure: CBCL }\end{array}$ & $\begin{array}{l}\text { Measure: The balloons } \\
\text { task } \\
\text { Stimulus: Child }\end{array}$ & $\begin{array}{l}\text { children's age. } \\
\text { Age, gender }\end{array}$ & $\begin{array}{l}\text { Fear } \\
\text { Grouped - Happy, sad and } \\
\text { Neutral (Externalising) }\end{array}$ \\
\hline
\end{tabular}




\begin{tabular}{|c|c|c|c|c|c|c|}
\hline Paper & Sample Characteristics & $\begin{array}{l}\text { Sample Size, Age } \\
\text { Range (Years) and } \\
\% \text { Female }\end{array}$ & $\begin{array}{l}\text { Type of Externalising } \\
\text { Problem and Measure }\end{array}$ & $\begin{array}{l}\text { Measure of FER and } \\
\text { Stimulus }\end{array}$ & Control variables & $\begin{array}{l}\text { Findings and Emotions } \\
\text { Tested } \\
\text { (underlined if sig. } \\
\text { impairment identified) }\end{array}$ \\
\hline $\begin{array}{l}\text { Sharp et al. } \\
\text { (2015) }\end{array}$ & $\begin{array}{l}\text { >Netherlands: Children from elementary schools } \\
\text { SES: not reported } \\
\text { Ethnicity: } 75 \% \text { Caucasian, } 25 \% \text { other }\end{array}$ & $\begin{array}{l}\mathrm{N}=417 \\
\text { Age: } 10-12 \\
\text { Female: } 46 \%\end{array}$ & $\begin{array}{l}\text { CU traits } \\
\text { Measure: YPI-CV }\end{array}$ & $\begin{array}{l}\text { Measure: CET } \\
\text { Stimulus: Adult faces, } \\
\text { eye region only }\end{array}$ & $\begin{array}{l}\text { Verbal intelligence, } \\
\text { gender, age }\end{array}$ & $\begin{array}{l}\text { Grouped - Happy \& Sad } \\
\text { (CU traits) }\end{array}$ \\
\hline $\begin{array}{l}\text { White et al. } \\
\text { (2016) }\end{array}$ & $\begin{array}{l}\text { >USA: Pre-schoolers from paediatric clinic waiting } \\
\text { rooms } \\
\text { SES: } 46 \% \text { living in poverty } \\
\text { Ethnicity: } 45 \% \text { African American, } 22 \% \text { European } \\
\text { American, } 31 \% \text { Hispanic, } 1 \% \text { other }\end{array}$ & $\begin{array}{l}N=337 \\
\text { Age: } 3-7 \\
\text { Female: } 55 \%\end{array}$ & $\begin{array}{l}\text { Low concern \& } \\
\text { punishment } \\
\text { insensitivity } \\
\text { Measure: MAP-DB }\end{array}$ & $\begin{array}{l}\text { Measure: Emotional } \\
\text { faces task, NimStim } \\
\text { stimulus } \\
\text { Stimulus: Adult - male } \\
\text { \& female, mixed } \\
\text { ethnicity }\end{array}$ & $\begin{array}{l}\text { Impulsivity, } \\
\text { irritability, } \\
\text { aggression \& IQ }\end{array}$ & $\begin{array}{l}\text { Happy } \\
\text { Anger } \\
\underline{\text { Fear Low concern }(\mathrm{CU}} \\
\text { trait })\end{array}$ \\
\hline $\begin{array}{l}\text { Boakes et al. } \\
\text { (2008) }\end{array}$ & $\begin{array}{l}\text { >Australia: Diagnosed with ADHD. Control } \\
\text { matched for age from the community sample } \\
\text { SES and Ethnicity: Not reported }\end{array}$ & $\begin{array}{l}24 \text { ADHD }(+24 \\
\text { HCs) } \\
\text { Age: } 7-12 \\
\text { Female: } 0 \%\end{array}$ & $\begin{array}{l}\text { ADHD } \\
\text { Measure: ADHD } \\
\text { diagnosis, CBCL, } \\
\text { SNAP-IV }\end{array}$ & $\begin{array}{l}\text { Measure: FAIT using } \\
\text { stimuli created from } \\
\text { television shows. } \\
\text { Stimulus: Cartoons \& } \\
\text { photos - no main effect } \\
\text { found }\end{array}$ & $\begin{array}{l}\text { Verbal and } \\
\text { performance IQ }\end{array}$ & $\begin{array}{l}\text { Happiness } \\
\text { Surprise } \\
\text { Anger } \\
\text { Sadness } \\
\text { Fear (ADHD) } \\
\text { Disgust (ADHD) }\end{array}$ \\
\hline $\begin{array}{l}\text { Kats-Gold et } \\
\text { al. (2007) }\end{array}$ & $\begin{array}{l}\text { Israel: Elementary schools. Study group 'at risk of' } \\
\text { ADHD, controls were low in ADHD } \\
\text { SES: Middle SES } \\
\text { Ethnicity: } 15 \% \text { were immigrants }\end{array}$ & $\begin{array}{l}50 \text { ADHD } \\
(+61 \text { HC's }) \\
\text { Age: } 9-11 \\
\text { Female: } 0 \%\end{array}$ & $\begin{array}{l}\text { Externalising \& } \\
\text { internalising } \\
\text { Measure: CCRS-R-S } \\
\text { \& the SSRS }\end{array}$ & $\begin{array}{l}\text { Measure: Ekman and } \\
\text { Friesen (1975) } \\
\text { Stimulus: Adult, men \& } \\
\text { women, black \& white } \\
\text { photos }\end{array}$ & $\begin{array}{l}\text { Parental education, } \\
\text { child age, } \\
\text { immigration status } \\
\text { and child } \\
\text { intelligence }\end{array}$ & $\begin{array}{l}\text { Grouped - Happy, Sad, } \\
\text { Anger and Fear (ADHD) }\end{array}$ \\
\hline $\begin{array}{l}\text { Woodworth \& } \\
\text { Waschbusch } \\
\text { (2008) }\end{array}$ & $\begin{array}{l}\text { >Canada: Programme for behaviour problems. } \\
\text { Control sample included } 6 \text { with ADHD } \\
\text { SES: Median family income was } \$ 40000 \text { (study \& } \\
\text { control) Ethnicity: } 84.3 \% \text { Caucasian, } 4.3 \% \text { African } \\
\text { Canadian, } 11.4 \% \text { in other ethnic categories }\end{array}$ & $\begin{array}{l}56 \mathrm{CP} \text { or } \mathrm{CP}+\mathrm{CU} \\
(+17 \mathrm{HCs}) \\
\text { Age: } 7-12 \\
\text { Female: } 25 \%\end{array}$ & $\begin{array}{l}\text { CP } \\
\text { Measure: DBDRS }\end{array}$ & $\begin{array}{l}\text { Measure: Ekman and } \\
\text { Friesen (1976) } \\
\text { Stimulus: Adult - male, } \\
\text { female \& cartoon - } \\
\text { Responses collapsed }\end{array}$ & $\begin{array}{l}\text { Age, sex, IQ and } \\
\text { ADHD }\end{array}$ & $\begin{array}{l}\text { Happy } \\
\text { Sad }(\mathrm{CU} \text { traits \& CP) } \\
\text { Surprise } \\
\text { Disgust } \\
\text { Anger } \\
\text { Fear }\end{array}$ \\
\hline $\begin{array}{l}\text { Corbett \& } \\
\text { Glidden }(2000)\end{array}$ & $\begin{array}{l}\text { >USA: Elementary school. Children with a } \\
\text { diagnosis of ADHD and control group matched for } \\
\text { age, gender \& SES } \\
\text { SES: Groups matched on SES index } \\
\text { Ethnicity: not reported }\end{array}$ & $\begin{array}{l}37 \text { ADHD }(+37 \\
\text { HCs) } \\
\text { Age: } 6-8 \\
\text { Female: not } \\
\text { reported }\end{array}$ & $\begin{array}{l}\text { ADHD } \\
\text { Measure: Diagnosis of } \\
\text { ADHD }\end{array}$ & $\begin{array}{l}\text { Measure: Ekman and } \\
\text { Friesen (1976) } \\
\text { Stimulus: Adult }\end{array}$ & Age and gender & $\begin{array}{l}\text { Grouped - Happy, sad, } \\
\text { surprise, disgust, anger, } \\
\text { fear \& Neutral (ADHD) }\end{array}$ \\
\hline $\begin{array}{l}\text { Pelc et al. } \\
\text { (2006) }\end{array}$ & $\begin{array}{l}\text { >Belgium: Children with ADHD in mainstream } \\
\text { schools } \\
\text { SES and Ethnicity: Not reported }\end{array}$ & $\begin{array}{l}30 \text { ADHD } \\
(+30 \mathrm{HCs}) \\
\text { Age: } 7-12 \\
\text { Female: } 23 \%\end{array}$ & $\begin{array}{l}\text { ADHD } \\
\text { Measure: Diagnosis of } \\
\text { ADHD }\end{array}$ & $\begin{array}{l}\text { Measure: Facial } \\
\text { expressions (Hess and } \\
\text { Blairy) } \\
\text { Stimulus: Adult - Male } \\
\text { \& female, } 2 \text { intensities }\end{array}$ & None stated. & $\begin{array}{l}\text { Happy } \\
\text { Sad ADHD } \\
\text { Disgust } \\
\text { Anger ADHD }\end{array}$ \\
\hline $\begin{array}{l}\text { Shapiro et al. } \\
(1993)\end{array}$ & $\begin{array}{l}\text { >USA: ADHD and control subjects from } \\
\text { participants of a school intervention for ADHD }\end{array}$ & $\begin{array}{l}67 \mathrm{ADHD}(+38 \\
\mathrm{HCs})\end{array}$ & ADHD & $\begin{array}{l}\text { Measure: MNTAP } \\
\text { battery }\end{array}$ & Sex, age, memory & $\begin{array}{l}\text { Grouped - Happy, Sad, } \\
\text { Anger and Fear (ADHD) }\end{array}$ \\
\hline
\end{tabular}

Page 34 
Key: ACES (Assessment of Children's Emotional Skills); APSD (Antisocial Process Screening Device); CARE (Children and Adolescents Recognition of Emotion); CBCL (Child Behaviour Checklist) CCRS-R-S (Conner's Rating System Revised); CET (Child Eyes Test); CSBS-TF (Children's Social Behaviour Scale - Teacher Form); CTRS-R (Revised Conner's Teacher Rating Scale); DANVA (Diagnostic Analysis of Nonverbal Accuracy); DAWBA (Development And Wellbeing Assessment); DBDRS (Disruptive Behaviour Disorder Rating Scale); DICA-R (Diagnostic Interview for Children and Adolescents-Revised); ECBI (The Eyberg Child Behavior Inventory); FACS (Facial Action Coding System); FAIT (Facial Affect Interpretation Task); HCs (Healthy Controls); ICU (Inventory of Callous-Unemotional Traits); MAP-DB

Eyberg Child Behavior Inventory); FACS (Facial Action Coding System); FAIT (Facial Affect Interpretation Task); HCs (Healthy Controls); ICU (Inventory of Callous-Unemotional Traits); MAP-DB
(Multidimensional Assessment Profile of Disruptive Behaviour); MNTAP (Minnesota Test of Affective Processing); MPAFC (Montréal Pain and Affective Face Clips); NimStim (A set of facial expression stimuli); (Multidimensional Assessment Profile of Disruptive Behaviour); MNTAP (Minnesota Test of Affective Processing); MPAFC (Montréal Pain and Affective Face Clips); NimStim (A set of facial expression stimuli); PSBS-T (Preschool Social Behavior Scale -Teacher Form); SDQ (Strengths and Difficulties Questionnaire); SES (Socio Economic Status); SNAP-IV (Swanson, Nolan, and Pelham Teach
SSRS (Social Skills Rating System); UNSW CU scale (The University of New South Wales Callous Unemotional Scal; YPI-CV (Youth Psychopathic Traits Inventory - Child Version. 
Page 36 